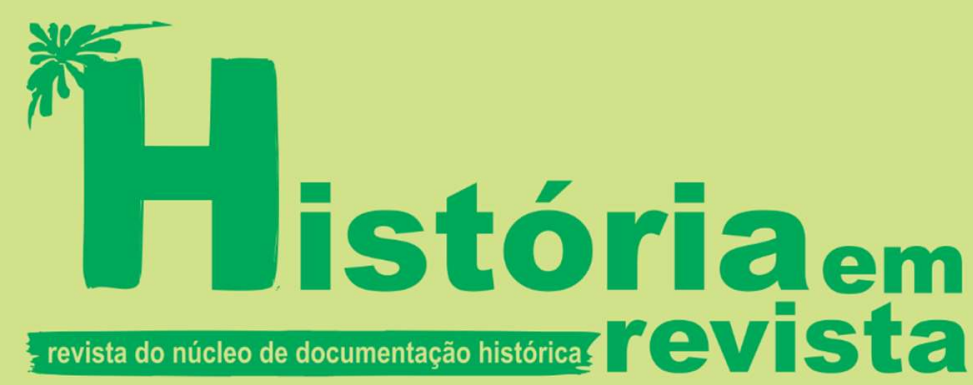

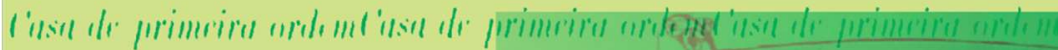

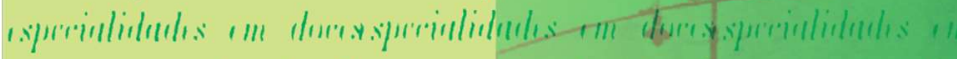

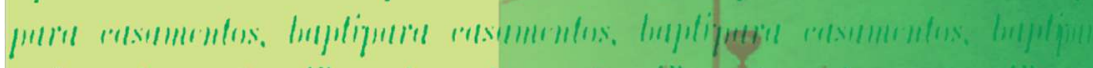

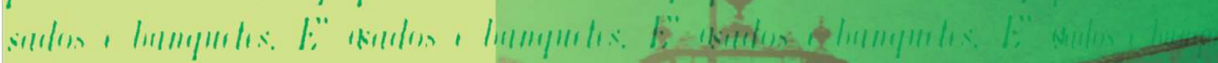

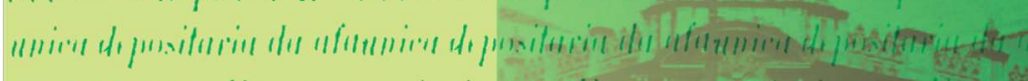

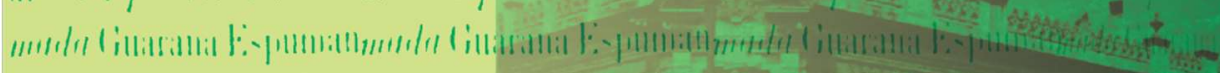

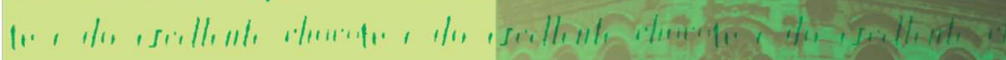

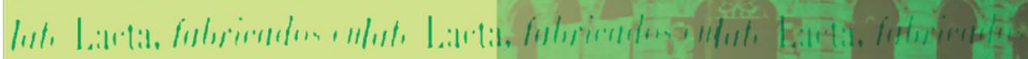

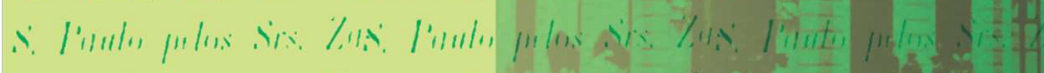

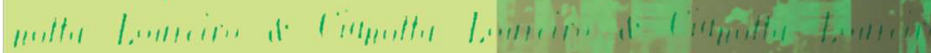

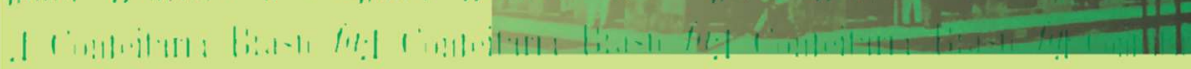




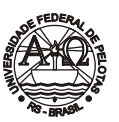

Obra publicada pela Universidade Federal de Pelotas Reitor: Pedro Rodrigues Curi Hallal Vice-Reitor: Luis Isaías Centeno do Amaral

Chefe de Gabinete: Aline Elias Lamas

Pró-Reitor de Graduação: Maria de Fátima Cóssio

Pró-Reitor de Pesquisa e Pós-Graduação: Flávio Fernando Demarco

Pró-Reitor de Extensão e Cultura: Francisca Ferreira Michelon

Pró-Reitor de Planejamento e Desenvolvimento: Otávio Martins Peres

Pró-Reitor Administrativo: Ricardo Hartlebem Peter

Pró-Reitor de Infra-estrutura: Julio Carlos Balzano de Mattos

Pró-Reitor de Assuntos Estudantis: Mário Renato de Azevedo Jr.

Pró-Reitor de Gestão Pessoas: Sérgio Batista Christino

\section{CONSELHO EDITORLAL}

Representante das Ciências Agronômicas: Guilherme Albuquerque de Oliveira Cavalcanti (Titular), Cesar Valmor Rombaldi (suplente) e Fabrício de Vargas Arigony Braga (suplente) | Representantes da Área das Ciências Exatas e da Terra: Adelir José Strieder (titular) e Juliana Pertille da Silva (suplente) | Representante da Área das Ciências Biológicas: Raquel Ludke (suplente) | Representante da Área das Engenharias e Computação: Darci Alberto Gatto | Representantes da Área das Ciências da Saúde: Claiton Leoneti Lencina (titular) e Giovanni Felipe Ernst Frizzo (suplente) | Representante da Área das Ciências Sociais Aplicadas: Célia Helena Castro Gonsales | Representante da Área das Ciências Humanas: Charles Pereira Pennaforte e Guilherme Camargo Massaú (suplente) | Representantes da Área das Linguagens e Artes: Josias Pereira da Silva (titular) e Maristani Polidori Zamperetti (suplente)

\section{INSTITUTO DE CIÊNCLAS HUMANAS}

Diretor: Prof. Dr. Sidney Gonçalves Vieira

Vice-Diretor: Prof. Dr. Sebastião Peres

\section{NÚCLEO DE DOCUMENTACÃO HISTÓRICA}

Coordenadora:

Prof ${ }^{a}$ Dra. Lorena Almeida Gill

Membros do NDH:

Prof ${ }^{a}$ Dra. Beatriz Ana Loner

Prof ${ }^{a}$ Dra. Lorena Almeida Gill

Prof. Dr. Paulo Ricardo Pezat

Prof. Dr. Aristeu Elisandro Machado Lopes

Técnico Administrativo:

Paulo Luiz Crizel Koschier

HISTÓRIA EM REVISTA - Publicação do Núcleo de Documentação Histórica

Comissão Editorial:

Prof. Dr. Aristeu Elisandro Machado Lopes

Prof ${ }^{a}$ Dra. Beatriz Ana Loner

Prof ${ }^{a}$ Dra. Lorena Almeida Gill

Prof. Dr. Paulo Ricardo Pezat

Conselho Editorial:

Prof ${ }^{a}$ Dra. Helga I. Landgraf Piccolo (UFRGS)

Prof. Dr. René Gertz (UFRGS) (PUCRS)

Prof. Ms. Mario Osorio Magalhães (UFPel)

Prof. Dr. Temístocles A. C. Cezar (UFRGS)

Profa. Dra. Beatriz Teixeira Weber (UFSM)

Prof ${ }^{a}$. Dra. Maria Cecília V. e Cruz (UFBA)

Prof. Dr. Marcelo Badaró Mattos (UFF)

Profa. Dra. Joan Bak (Univ. Richmond - USA)

Prof. PhD Pablo Alejandro Pozzi (Universidad de Buenos Aires).

Prof. Tommaso Detti (Università Degli Studi di Siena)

Editor: Prof. Dr. Aristeu Elisandro Machado Lopes

Editoração e Capa: Paulo Luiz Crizel Koschier

Editora e Gráfica Universitária

R Lobo da Costa, 447 - Pelotas, RS - CEP 96010-150 |

Fone/fax: (53) 32278411

e-mail: editora@ufpel.edu.br

\section{Impresso no Brasil}

Edicão: 2017

ISSN - 1516-2095

Dados de catalogação na fonte: Aydê Andrade de Oliveira - CRB - 10/864

História em revista / publicação do Núcleo de Documentação Histórica. Instituto de Ciências Humanas. Universidade Federal de Pelotas. v.23, (dez. 2017). - Pelotas: Editora da UFPel, 2017.

$1 \mathrm{v}$.

Anual

ISSN 1516-2095

1. História - Periódicos. I. Núcleo de Documentação Histórica. Instituto de Ciências Humanas. Universidade Federal de Pelotas. CDD 930.005

\section{Indexada pela base de dados Worldcat Online Computer Library Center}

\section{PEDE-SE PERMUTA} WE ASK FOR EXCHANGE

UFPel/NDH/Instituto de Ciências Humanas

Rua Cel. Alberto Rosa, 154

Pelotas/RS - CEP: 96010-770

Caixa Postal 354

Fone: (53) 32843208

\section{http://wp.ufpel.edu.br/ndh/} e-mail:ndh.ufpel@gmail.com 


\title{
VOCÊ PARECE A ANGELA DAVIS: TENSÕES NAS REPRESENTAÇÕES DE ESTUDANTES UNIVERSITÁRIOS DURANTE A Ditadura MILITAR No Brasil
}

\author{
YOU LOOK LIKE ANGELA DAVIS: TENSIONS ON \\ UNDERGRADUATED STUDENTS'S REPRESENTATIONS DURING \\ BRAZILIAN MILITARY DICTATORSHIP
}

Gabriel Vicente França ${ }^{1}$

\begin{abstract}
Resumo: Este artigo apresenta os primeiros resultados de uma pesquisa que estuda o cotidiano de estudantes de ensino superior durante a Ditadura Militar no Brasil. Para tanto, faz uma leitura do romance "As Meninas" (1973), de Lygia Fagundes Telles, e a coloca em confronto com a leitura de editoriais do jornal O Estado de São Paulo, produzidos entre 1967 e 1973, de modo a encontrar pontos de tensão nas representações sobre a juventude universitária em ambos os discursos. Com essa finalidade, parte-se de arcabouço conceitual desenvolvido por Michel de Certeau e Roger Chartier.
\end{abstract}

Palavras-chave: cotidiano de estudantes universitários; Ditadura Militar; Juventude.

\section{Introdução}

Este artigo concentra os resultados iniciais de uma pesquisa de mestrado em História da Educação que tem como objeto de pesquisa o cotidiano de estudantes de ensino superior durante a Ditadura Militar. Para tanto, parte-se da leitura do romance As Meninas (1973), de Lygia Fagundes Telles, para encontrar indícios que permitam uma interpretação renovada dos acontecimentos que tiveram palco na virada dos anos 1960 para os anos 1970. Assim, este texto se beneficia da renovação das fontes apresentada por Roger Chartier no início dos anos 1990, e que produziu grande impacto nas pesquisas históricas realizadas no campo educacional.

O romance, lançado em dezembro de 1973 pela José Olympio Editora, tematiza a vida de três garotas estudantes de ensino superior, Lorena, Lia e Ana Clara, que viviam sob o teto de um pensionato de freiras na cidade de São Paulo. Sua densidade narrativa, seu projeto literário e sua ampla circulação permitem que se observem, por um ponto de vista bastante privilegiado, as "meadas das relações e tensões" (CHARTIER, 1991, p. 177) constituintes da

${ }^{1}$ Mestrando no programa de pós graduação em educação da Faculdade de Educação da Universidade de São Paulo. Contato: gvfranca@gmail.com 
sociedade. A obra permaneceu na lista dos livros mais vendidos do Suplemento Literário do jornal O Estado de São Paulo até dezembro do ano seguinte. Nos mais de quarenta anos que separam sua primeira edição do tempo presente, foi editado por diversas companhias, sendo atualmente publicado pela editora Companhia das Letras. Bem acolhido por público e crítica, o romance recebeu uma adaptação cinematográfica nos anos 1990, e figura ainda hoje como um dos livros de maior sucesso da autora.

A interpretação do romance é aqui orientada por conceitos apresentados por Michel de Certeau em A invenção do cotidiano (2014), o que dirigiu as atenções da leitura para os modos de vestir, de falar e de crer, entre outras artes de fazer, das protagonistas. É para responder as indagações a respeito de como as personagens inventavam seu cotidiano que se procedeu dessa forma. E os primeiros resultados permitem a identificação de pontos pelos quais a autora se propôs a criar interlocução com outras representações a respeito da juventude do período, produzindo uma visão contra-hegemônica e dissonante.

É importante ressaltar que a imagem produzida sobre a juventude, em geral, e sobre os estudantes universitários, em particular, no final dos anos 1960 não foi sempre a mesma. Helena Wendel Abramo aponta que houve um processo de mudança que percorreu os tempos, partido de uma visão negativa que se plasmou em uma visão positiva (ABRAMO, 1997, p. 31). Partimos do pressuposto que esse processo se explica melhor com a conceituação de "lutas de representações", conforme proposta por Chartier (1990), e das quais entendemos que Lygia Fagundes Telles, dada sua posição de destaque nos campos literário e intelectual, tomou parte.

Por outro lado, a universidade - instituição que se estabelece no Brasil apenas ao final da República Velha - assume centralidade na vida do país a partir das mudanças ocorridas na economia com o processo de industrialização e reorganização do mercado de trabalho. Pouco a pouco, a obtenção de um diploma de nível superior veio a ser condição necessária para que as camadas médias da população tivessem garantida sua ascensão social (CUNHA, 1989, p.63), a estrutura das empresas públicas e privadas se tornava mais complexa e exigia de maior qualificação de seus quadros dirigentes (CANO, 2015, p. 459), e o estabelecimento de uma burocracia que nascia com a consolidação do Estado Nacional (BRESSER-PEREIRA, 2007, p. 15) também via na universidade sua garantia de futuro.

Esse movimento complexo fez da universidade brasileira o centro das atenções de parte da sociedade, que lançava suas preocupações para o que lá 
ocorria, de maneira similar ao que se passava em outros lugares do mundo, onde greves e protestos estudantis, não sendo incomum sua tematização pela literatura. Amuleto, de Roberto Bolaño, retrata uma invasão do exército à Faculdade de Filosofia da Universidade Autônoma do México; As jovens damas vermelhas cada vez mais belas, de Frédéric Fajardie, traz as lembranças de um militante do maio de 1968 francês em suas páginas; o japonês Haruki Murakami, por sua vez, conta de um episódio de greve estudantil vivida por seu personagem principal em Tóquio, no mesmo ano que nunca acabou, no romance Norwegian Wood.

É essa a universidade que frequentam as três personagens principais do romance de Lygia Fagundes Telles: objeto de debate por toda a sociedade, foco de interesse das camadas médias, centro de uma transformação cultural com ares de revolução. Lorena, Lia e Ana Clara vivem seus dramas ordinários à espera do fim de uma greve universitária e seu cotidiano pode ajudar a pensar a juventude sob a Ditadura Militar no Brasil. Para tanto, é importante localizar como é que o romance produziu interlocuções com outras representações sobre estudantes.

Desta forma, apresentam-se, na sequência, pontos de tensão existentes entre as representações sobre estudantes, tendo como objeto de diálogo o conteúdo opinativo publicado em editoriais do jornal paulista O Estado de São Paulo, durante o período de 1967 a 1973.

\section{Pontos de tensão entre representações de estudantes}

No centro da atenção da grande imprensa e provocando as mais variadas reações por parte da sociedade, os estudantes universitários brasileiros vivenciavam, ao final dos anos 1960, momentos inéditos em sua curta trajetória de existência. Embora houvesse ensino superior no Brasil que remontava ao século XIX, a universidade só é consolidada nos estertores da República Velha, sendo a figura de estudante universitário bem recente quando o romance de Lygia Fagundes Telles se lança a público. Eram inicialmente pouquíssimos, mas o número de matrículas no ensino superior acompanha o desenvolvimento econômico e industrial do país, chegando a ponto de, na metade dos anos 1960, existirem mais estudantes com condições de cursar a universidade do que vagas disponíveis para que seus estudos acontecessem. Não eram poucos, portanto, os interesses e paixões despertados por essa nova condição de juventude no Brasil.

Como forma de melhor localizar o romance As Meninas nesse 
processo de luta de representações, escolheu-se proceder à leitura de editoriais do jornal O Estado de São Paulo, com vistas a encontrar pontos de tensão existentes entre a representação que se dava em suas páginas e alguma outra que também tratasse dessa juventude incipiente.

Fundado como "A Província de São Paulo", em 1875, o "Estadão" é um dos noticiosos paulistas mais tradicionais. Frequentemente associado às elites do estado, exerceu papel importante na fundação da Universidade de São Paulo, em 1934: é a partir de um inquérito organizado pelo jornal e dirigido por Fernando de Azevedo que se dá a criação desta instituição que serve como polo aglutinador da intelectualidade paulista desde então. Daí decorre a presença de diversos textos que tratam da universidade, tema muito caro ao jornal, no espaço nobre que representa seu editorial. Cabe destacar que optouse pelo texto dos editoriais a partir do entendimento de que ali se expressam as opiniões do jornal - de seus donos, de seus editores-chefes - em detrimento da construção de uma narrativa informativa, podendo haver discrepâncias com relação ao conteúdo de matérias e reportagens apresentadas no restante das páginas da publicação.

De modo a encontrar um recorte temporal plausível, estabeleceu-se como marco inicial o ano de 1967, quando os estudantes que tinham obtido nota para ingressar na universidade, mas que não tinham vaga, organizaram uma greve, chamada por "Greve dos Excedentes", e como marco final o ano de publicação do romance, 1973.

Com visões distintas a respeito da juventude e, em particular, com relação às formas de manifestação dos estudantes, o romance e os editoriais apresentam possibilidades interpretativas ricas: pretende-se demonstrar, a seguir, que a visão de uma juventude planificada e ingênua, projetada pelo jornal, contrastava com uma construção polifônica e caleidoscópica que se depreende pela leitura do romance.

Para tanto, serão apresentadas no correr desse texto apreciações acerca do projeto estético e literário do romance de Lygia Fagundes Telles, destacando aspectos da materialidade do livro e elementos constituintes da narrativa de As Meninas, que se confrontarão com trechos de editoriais do jornal que tratam de estudantes universitários, para, a seguir, dar-se um mergulho no texto literário em si, de modo a apresentar conflitos existentes entre essas representações.

A tentativa de diálogo entre as palavras publicadas na página 3 do Estadão e o que se passava por entre as paredes do Pensionato Nossa Senhora de Fátima, lar de Lorena, Lia e Ana Clara em As Meninas, tem de começar por 
algum lugar. E não há maneira melhor do que apresentando as linhas gerais do romance de Lygia Fagundes Telles.

Afinal, o que Lygia pretendia com essas meninas?

\section{As Meninas}

\subsection{Caracterização do romance}

Com a utilização de técnica literária que mescla pontos de vista e narradores, ora sendo escrito em primeira pessoa, ora em terceira, o texto apresenta os conflitos vivenciados por três estudantes que moram no Pensionato Nossa Senhora de Fátima, na cidade de São Paulo.

Lia, chamada por Lião pelas outras meninas, é estudante de ciências sociais, mas trancou o curso para se juntar à luta armada contra a Ditadura Militar. Seu namorado, Miguel, está preso e ela é figura importante na organização clandestina de que faz parte; é responsável por manter o "aparelho", imóvel no qual acontecem as reuniões do grupo subversivo, por dar cursos de formação e por organizar e executar ações políticas, além de coligir material publicado em jornais para o grupo. Lia aparece pouco no pensionato Nossa Senhora de Fátima, sempre envolta com alguma questão mais importante. Tem uma relação muito difícil com Ana Clara, a quem enxerga como uma pessoa doente em função do uso de drogas, mas de quem não consegue mais se compadecer, e é um dos alvos da mania de limpeza e arrumação de Lorena, a quem sempre recorre quando precisa de dinheiro ou de um carro para as ações da organização clandestina. Através de suas ações e de suas contradições são apresentadas imagens a respeito de uma militante estudantil da época, que optou por largar o curso em função da guerrilha armada.

Lorena é filha de uma família endinheirada que caminha rapidamente para a falência. Sua imagem tipifica a estudante burguesa do interior que se mudou para São Paulo para estudar. A trajetória de seus familiares parece apontar o declínio de uma sociedade enraizada na economia brasileira da primeira metade do século XX e que precisa se adaptar às vicissitudes do processo de industrialização que se intensifica no país no momento em que se passa o romance. A garota cursa Direito na USP, mas a faculdade está em greve. Vive em permanente conflito com sua sexualidade, pois é virgem e quer ter sua primeira noite com o amante que é casado e tem uma família com muitos filhos. A mãe se casou com um homem muito mais jovem após o falecimento do primeiro marido e manda dinheiro para a filha de tempos em 
tempos. Dinheiro que circula entre as três amigas, já que Lorena fica presa no pensionato permanentemente, trocando os discos da vitrola, ora ouvindo Jimi Hendrix, ora Chopin, com uma permanente mania por limpeza e perfumes. Cuida carinhosamente das amigas enquanto espera a volta de seu gato Astronauta e a ligação do amante.

Já Ana Clara, chamada de Ana Turva pelas amigas, está prometida em casamento para um rico industrial, mas precisa ser virgem para consolidar as bodas, o que é um problema a ser resolvido com a ajuda do dinheiro de Lorena, uma vez que vive intensamente sua relação com um traficante, Max, de quem engravidou e com quem compartilha horas sem fim de consumo de drogas. Linda como uma modelo de revista, sua condição física deteriora-se a cada página do romance, ao lembrar de todos os casos de violência sexual por que passou enquanto criança e adolescente e à medida que se aproxima a data de seu casamento com o industrial. Estudante de psicologia, a personagem tipifica a transição social por meio da obtenção de um diploma de nível superior. No correr do romance, tem seu curso trancado e ambas as amigas se preocupam desesperadamente com ela, antevendo seu fim inexorável.

A crítica atribui a essas três personagens contornos de realidade, de modo a apresentá-las como representantes fidedignas de uma juventude específica, de carne e osso. Como exemplo, toma-se como exemplo o trabalho do poeta e ensaísta José Paulo Paes, que afirma que as personagens "tipificam os caminhos ou descaminhos com que se defrontava a juventude universitária dos anos 60-70, quando o regime militar se firmava sob a égide de uma repressão cuja violência a atingiu de perto" (PAES, 1998, p, 78). Já o escritor e professor Cristóvão Tezza, em posfácio à atual edição de As Meninas, diz que "pode-se dizer que elas se definem a partir de três 'arquétipos', ou figuras da época” (TEZZA, 2009, p. 288). Por fim, Paulo Emílio Salles Gomes, marido de Lygia Fagundes Telles quando da escrita e da publicação da obra, escreve na orelha da primeira edição do livro, ainda pela José Olympio Editora: "Porque o que une essas três jovens brasileiras não é apenas a amizade, mas a circunstância de serem filhas do mesmo lugar e do mesmo tempo" (SALLES GOMES, 2009, p. 295).

\subsection{Juventude e polifonia: liberdade através das palavras}

Convém notar, no que tange ao texto do romance, que a narrativa se dá quase que permanentemente por meio das palavras das próprias personagens principais, Lorena, Lia e Ana Clara; eventual e raramente aparece um narrador onisciente. Ao longo das 279 páginas do texto, são 79 trocas de narradora. 
Além dessa efusiva mudança de ponto de enunciação, outros elementos também aparecem, como citações literais de outros textos, o diário de uma das personagens, e até mesmo o que seria a transcrição de um panfleto clandestino que serviria para denunciar as ações de tortura durante a Ditadura Militar. Ao longo de todo o romance, as personagens estão imersas em músicas ou se referem a leituras e a filmes. É como se os produtos culturais do período fossem coadjuvantes sempre presentes na narrativa. Por vezes, são objeto de debate e de divergência entre as meninas, por vezes são apenas apreciados durante um diálogo ou uma reflexão mais demorada e profunda. Por vezes também fazem referência a situações específicas que transcorrem no romance, como ao uso de drogas por Jimi Hendrix, em alusão ao vício de Ana Clara, ou quando o livro O segundo Sexo, de Simone de Beauvoir serve de pretexto para Lorena relatar que quase manteve uma relação sexual com Lia.

Assim, é possível dizer que um primeiro aspecto fundamental do texto do romance é que ele não é portador apenas de uma voz, mas é sim construído por um conjunto de vozes que se articulam durante a narrativa, constituindo-se em uma composição polifônica. Mas essas vozes são características, pois enunciadas por personagens jovens, o que suscita interesse por parte da crítica literária.

Em entrevista concedida ao Estadão e publicada no jornal em 09 de dezembro de 1973, o que coincide com o lançamento público do romance, Lygia é perguntada se utilizou a "linguagem dos jovens" no texto. E ela responde:

Não vivo numa torre de marfim (...). Ora, vivendo no meio de gente e
escrevendo sôbre gente, como posso evitar que minhas personagens - gente
também e gente jovem - digam seus palavrões na hora certa? Ou mesmo fora
de hora, quem é que sabe das oportunidades? A palavra tem que ser livre. Ao
menos a palavra. E o palavrão (sic) (O Estado de São Paulo [OESP], 1973, p.
321).

A liberdade da linguagem, que aparece na superfície do texto, parece ser um indício revelador da tensão que corre nas entranhas do romance. "Usei uma linguagem completamente diferente nesse livro. Distante de tudo o que já fiz: tentei uma nova forma. Experimentei uma estrutura que fosse adequada às minhas personagens e não a mim mesma” (id. ibid.).

O projeto estético que é empreendido acaba por ser o resultado de uma determinada concepção a respeito da juventude do período: em uma sociedade que cerceava direitos, como ocorria durante a Ditadura Militar, as meninas jovens que viviam sob o teto do pensionato precisavam encontrar espaços para 
que suas palavras pudessem correr em liberdade.

\subsection{Um não lugar}

Essa liberdade através das palavras faz ressoar um dos temas que Michel de Certeau apresenta em A Invenção do Cotidiano (2014), o a existência de um utópico.

Com raízes etimológicas no grego, em que "topos" significa lugar e "u" é um prefixo de negação, o termo "utopia" foi cunhado pelo escritor inglês Thomas More em sua obra homônima, lançada em 1516. Nela, Utopia é uma ilha imaginária em que uma sociedade perfeita teria sido desenvolvida. Sem fazer alusão ao livro de More, Certeau retoma a etimologia da palavra para tratar de explicar uma de suas observações feitas no Brasil, ainda na década de 1970. Ele procurava entender a língua falada por lavradores em Pernambuco e tratava de analisar "as gestas de Frei Damião, herói carismático da região". É assim que descreve a situação:

O espaço distribuía o espaço de maneira a estratificá-lo em dois níveis. De um
lado, um espaço socioeconômico, organizado por uma luta imemorial entre
'poderosos' e 'pobres', apresentava-se como o campo das perpétuas vitórias dos
ricos e da polícia, mas também como o reinado da mentira (ali nunca se diz uma
verdade, a não ser em voz baixa e na roda dos lavradores (...)) Ali, sempre, os
fortes ganham e as palavras enganam. (...) Por outro lado, distinto desse espaço
polemológico e que apresenta à perspicácia os lavradores uma série inumerável
de conflitos, escondida sob o manto da língua falada, havia um espaço utópico
(...) (CERTEAU, 2014, p. 72 . Grifos no original)

Desse longo trecho retirado de A invenção do cotidiano, pode-se extrair uma ideia central. À divisão do espaço entre um lugar e um não-lugar corresponde a oposição entre o polemológico e o utópico. Isto é, a oposição entre um campo de forças, uma luta permanente, e um "lugar inexpugnável, por ser um não lugar, uma utopia" (CERTEAU, 2014, p.73-74). No caso dos lavradores pernambucanos estudados por Certeau, esse espaço inexpugnável era onde Frei Damião poderia aparecer como um milagre, um espaço de possibilidades, que coexiste com o da "experiência sem ilusões".

A partir da ideia de espaço estratificado que permite a coexistência de um lugar, caracterizado como polemológico, e de um não lugar, utópico e que permite o possível, a leitura de As Meninas aponta para elementos frutíferos para o debate sobre juventude.

Um trecho é bastante significativo dessa estratificação espacial no 
romance. Trata-se de um momento em que Lia e Lorena travam um longo diálogo. Lia está de saída do pensionato, ocupada com as tarefas da organização clandestina de que é militante e que estão sob sua responsabilidade. Lorena procura, por diversos meios, fazer com que a amiga fique um tempo maior para continuarem as conversas. As duas personagens, é importante dizer, são construídas como que em um contraponto, com características opostas: divergem e confrontam suas ideias permanentemente, com muitas diferenças bastante profundas de ponto de vista, mas que vão se complementando em meio a uma mesma melodia.

Na passagem que se transcreve abaixo, Lia - que é quem narra esse trecho - apresenta a oposição que há entre as duas a respeito da ideia de liberdade. Elas têm uma discussão a respeito do estado de saúde de Ana Clara e vão caminhando pelo jardim do pensionato com destino ao portão, objeto que marcará a separação das duas: Lia para a rua, por conta própria, Lorena, de volta para dentro, sob a proteção das freiras.

[Lorena] Tenta ainda me prender, não quero mesmo almoçar? E que tal uma volta no Corcel? Um sorvete no clube? Saio e bato o portão. Vejo-a como uma prisioneira através das grades do seu jardim. Sinto uma certa tristeza mas logo tenho vontade de rir. Ponto de vista: para ela a prisioneira não sou eu? (TELLES, 2009, p. 169. Grifos do autor)

O portão representa tanto o objeto físico quanto a barreira que separa o lugar e o não lugar. Para Lia, a vida transcorre do lado de fora do pensionato, na luta clandestina contra a ditadura, na espera pela liberdade do namorado que está preso e na possibilidade de fazer a revolução. Para Lorena, que só sai do pensionato esporadicamente, a vida é o que ela imagina enquanto aguarda uma ligação (que nunca acontece) do amante e esquenta água para fazer um chá. Para ambas, entretanto, a possibilidade de frequentarem os dois espaços é fundamental para que consigam desenrolar suas vidas.

Este aspecto dramático do romance - a presença de um não lugar, de um utópico - explicita uma característica fundamental da representação de juventude que se produz no romance: a necessidade de espaços em que ao menos a palavra seja livre.

\subsection{Um testemunho}

É, finalmente, importante apresentar que Lygia Fagundes Telles fala de um lugar muito bem delimitado sobre a juventude da virada dos anos 1960 para 1970. Ela não se sente parte das movimentações juvenis - completou seu 
$50^{\circ}$ aniversário no ano de lançamento da obra - , mas prefere se posicionar como alguém que tem condições de fazer observações argutas. Mais do que isso, pois não se coloca em uma torre de marfim, prefere fazer de seu romance um testemunho.

Essa dimensão é postulada logo quando do lançamento de As Meninas, e acaba por se repetir em entrevistas ao longo da carreira da autora. "Creio que o escritor - mais do que ninguém - deve ser o testemunho do seu tempo. Nesse depoimento deverá constar tudo o que o tocou mais fundamente. Ficará sendo essa sua verdade, doa a quem doer" (OESP, 1973, p. 321).

$\mathrm{O}$ mesmo tema se repete em entrevista à Revista Brasileira de Psicanálise, de 2008, quando trata objetivamente de As Meninas: "Esse romance foi escrito nos anos de chumbo, plena ditadura militar, 1970; sou eu, como escritora, uma testemunha desse nosso tempo e dessa nossa sociedade".

Assim, ao fazer de um romance que tem como personagens principais três garotas estudantes universitárias e que tem a liberdade da palavra como eixo estruturante da obra, Lygia produziu um testemunho muito peculiar. Contra-hegemônico e dissonante, ele produziu interlocuções com outras representações sobre a juventude.

Dentre elas, a do jornal O Estado de São Paulo.

\section{O Estadão}

\subsection{Monolito com pequenas fissuras}

O Jornal O Estado de São Paulo, o Estadão, foi fundado em 1875, quando se chamava "A Província de São Paulo." Jornal tradicional e de grande circulação no estado, tem vinculação com a elite e com a aristocracia paulista, sendo muitas vezes o meio pelo qual a voz desses setores sociais é propagada. Paralelamente a isso, foi fundamental para o estabelecimento da Universidade de São Paulo, reservando frequentemente parte de seu espaço opinativo para tratar dessa questão.

Os editoriais, que ocupavam longo espaço na página 3 do jornal, serviam como meio privilegiado para a exposição das opiniões da empresa jornalística a respeito dos acontecimentos do país. Lá é onde se faziam presentes as visões sobre governo, sociedade, economia e política, numa tradição que se mantém até os dias de hoje. Por não serem textos informativos, em oposição às reportagens do restante do noticioso, acabam por se apresentar como espaço privilegiado para a compreensão da representação acerca da 
juventude produzida pelo Estadão.

Assim como o romance de Lygia, o Estadão se colocava como observador atento dos acontecimentos. Ao contrário da obra literária, assume posição mais panfletária, muitas vezes dirigindo-se às autoridades com admoestações para que tomassem providência, ou exigindo delas mudanças de atitude para coibirem o que acontecia de errado. De sua visão característica, percebe-se com clareza o ataque às posições políticas alinhadas ao comunismo, fossem elas apresentadas pelos movimentos políticos brasileiros ou as que se processavam na Europa Oriental, um grande apreço pela democracia dos Estados Unidos e uma forte defesa da institucionalidade vigente no país então, sem que se considerasse o governo militar como parte de uma Ditadura.

Desta forma, o matizamento do texto deriva da posição política do jornal, não sendo raro que um evento de contestação - como um protesto estudantil, por exemplo - seja considerado positivo se estiver de acordo com as os posicionamentos políticos do jornal e negativo se estiver do outro lado da trincheira ideológica.

Um bom exemplo desta posição está presente em um editorial de abril de 1968, intitulado "Condenados a reviver o passado":

A uma parte da juventude norte-americana, a prosperidade, com seu vazio espiritual, torna ridícula e mesmo um contra-senso a luta por altos ideais nacionais ou históricos. O contrário do que se dá com a juventude comunista, profundamente enojada com os ideais que lhe pregam, os quais a põe disciplinada, em marcha, sem pensar e sem poder ter sentimentos, constituída em regimentos, em exércitos e em partidos missionários. (OESP, 1968a, p.3).

Isso faz com que a imagem da juventude projetada pelos editoriais seja construída sob influência dos modos como esta se comportava em relação aos pressupostos ideológicos do veículo. Em grande medida, é possível afirmar que o jornal enxergava uma juventude planificada, composta por uma grande maioria de pessoas que compartilhavam dos ideais expressos em suas páginas; vez ou outra, um grupo de mal-intencionados terminava por levar uma pequena parte dessa juventude para o caminho errado - o do comunismo.

"Trata-se de algo mais, de algo mais profundo e mais perigoso do que o inconformismo típico de todas as juventudes, da crise costumeira entra duas gerações", diz o Jornal no mesmo texto.

A juventude ocidental, pensamos naturalmente nos seus setores em que a militância violenta a projeta para as 'manchetes' dos jornais (...) parece rejeitar não apenas as estruturas sociais que lhe garantem a liberdade e a prosperidade. Rejeita também esses bens, negando-lhes a qualidade de valor (...) (OESP, id. ibid., p.3. Grifos do autor). 
A ação descrita pelo Jornal é realizada por uma militância violenta, que desvia os rumos naturais da juventude dos Estados Unidos, tida aqui como a juventude da liberdade e da prosperidade, a ponto de a projetar para as manchetes das primeiras páginas dos jornais. Essa movimentação política, segundo a visão apresentada pelo Jornal, só é possível se a juventude for desviada de seu rumo natural. $\mathrm{Na}$ linha de raciocínio aqui desenvolvida pelo Estadão, que nos parece exemplar de sua compreensão da juventude, não há possibilidade de que essas manifestações, que eram essencialmente contraculturais e contra a Guerra do Vietnã, tivessem surgido por obra e interesse dos próprios jovens que dela participaram.

Estabelece-se aqui uma das mais fundamentais dicotomias da representação produzida pelo O Estado de São Paulo: a juventude só tem protagonismo quando se movimenta de acordo com a ideologia do Jornal; quando se posiciona de forma diferente, não é autora de suas próprias ações, assumindo um caráter de passividade com relação a agentes mal intencionados. É, portanto, um bloco de pedra que apresenta algumas pequenas fissuras, de que se aproveitam alguns elementos externos.

\section{2. "Agentes da Mazorca"}

Em 1967, quando da doação de livros por parte do governo dos Estados Unidos para a Universidade de Brasília (UnB), os estudantes se organizaram para a realização de um protesto contra o Embaixador daquele país, que estaria presente em um evento nas dependências da Universidade. Àquele momento, o movimento estudantil considerava que os acordos que estavam em vias de se estabelecer entre o Ministério da Educação e Cultura (MEC) e a United States Agency for International Development (USAID) representavam o que havia de pior para as universidades brasileiras. Os Acordos MEC-USAID eram objeto de crítica por parte dos estudantes e a presença de uma figura de autoridade dos Estados Unidos dentro da UnB representava a personificação desses Acordos. A manifestação organizada pelos estudantes motivou um editorial do Estadão intitulado "Um papelão".

Nele, as movimentações dos estudantes de Brasília são diretamente associadas às "agitações bolchevistas", ao "extremismo marxista" e ao "primário fanatismo" de Che Guevara: "Preocupados ficamos quando a juventude, em sua generosa boa fé, se deixa iludir pelos agentes da mazorca e desliza até manifestações com as que acabamos de presenciar na Universidade de Brasília” (OESP, 1967, p.3). 
A juventude é desviada, mais uma vez, de seu rumo natural por meio de uma ação feita conscientemente de má fé. Neste caso, os "agentes da mazorca" são os que se associam com as ideologias da esquerda política e que se aproveitam das características puras da juventude para conduzi-la a um destino frontalmente oposto ao que a ela seria reservado naturalmente.

É a juventude espiritualmente pura pela sua própria natureza mas isenta, talvez por isso mesmo, de compreensão sôbre as peculiaridades humanas que diferenciam a nossa espécie da dos querubins e serafins. Só a maturidade (...) nos leva a condescender com as fraquezas e defeitos humanos e a procurar sua correção (...) (sic) (id. ibid., grifos do autor).

Destaca-se do trecho acima a oposição entre a juventude e a maturidade. Os jovens apresentam-se puros e sem condições de compreender as "peculiaridades humanas", habilidade que só se adquire com a idade. Essa deficiência juvenil derivaria de uma certa natureza da juventude, sobre a qual o texto falará ainda mais:

Desse natural e, no fundo, generoso pendor da mocidade, é que se valem os agitadores para deturpar os movimentos estudantis, atribuindo-lhes aspectos políticos da conveniência de ideologias alienígenas, quando é verdade que a responsabilidade pelas perturbações cabe sempre a uma insignificante minoria de mascarados ou estranhos à vida escolar e aos seus interesses e com a sensibilidade já embotada para o autêntico idealismo dos moços (id. ibid.).

É como se os estudantes só pudessem assumir posições políticas divergentes das tomadas pelo Jornal se estivessem sob influência dos "agentes da mazorca".

É necessário, portanto, sublinhar um traço que caracteriza a mocidade que subjaz desse editorial: a incapacidade de a juventude formular suas próprias ideias.

\subsection{Energúmenos}

Em 1968, movidos por um sentimento que remontava ao começo da década, quando a União Nacional dos Estudantes apresentou a reforma da universidade como uma das reformas de base a serem realizadas pelo governo de João Goulart, os estudantes paulistas empreendiam sua luta contra os acordos MEC-USAID. Uma das formas de combater as medidas que se pretendiam implementar por meio da legislação foi com a discussão da Reforma Universitária. Por um lado, o governo federal procurava elaborar um plano de reformas que alterasse estruturalmente o ensino superior do país, procurando alinhá-lo às necessidades de desenvolvimento que derivavam do 
projeto político que era implementado desde Brasília; por outro, o movimento estudantil fazia discussões intensas para postular a reforma que levaria à universidade que, segundo sua visão, a população brasileira precisava.

Uma das ações que ocorreu na capital paulista foi a tomada do prédio da Reitoria da Universidade de São Paulo (USP) pelos estudantes. A ocupação, que o Jornal tratou como "cenas deprimentes" que geraram um "sentimento de profunda revolta", foi duramente criticada em editorial intitulado "A crise nas nossas universidades", de 15 de junho de 1968. O texto procurou construir a ideia de que ações violentas levam a reações mais violentas, e cita situações similares ocorridas no Uruguai, na Argentina e na França.

A grande maioria dos estudantes, de acordo com a leitura empreendida pelo Estadão, refutava esse tipo de manifestação:

Só os próximos dias poderão confirmar ou desmentir essa impressão de que o
bom senso tende a impor-se, por meio da procura de um diálogo construtivo.
De qualquer modo não cometemos a injustiça de responsabilizar a classe
estudantil no seu conjunto pelas brutalidades praticadas pelo grupo de
energúmenos que, além de ferir profundamente a dignidade de nossa primeira
Universidade, desceu ainda ao requinte selvático de emporcalhar os muros da
sua Reitoria com slogans reveladores da mentalidade vandálica dos seus autores
(OESP, 1968b, p. 3, grifos do autor).

A associação das ações ocorridas na Reitoria da USP com imagens bestiais se contrapõe com a construção efetuada quanto à juventude que se alinhava ideologicamente com o Estadão.

Os verdadeiros sentimentos da juventude universitária brasileira são expressos
pelo número cada vez mais elevado de moços que se oferecem ao Exército para
participarem da Operação Rondon. Esses rapazes, sim, refletem a imagem
autêntica da nossa mocidade, identificando-se com os anseios mais nobres da
grei (id. ibid.).

Essa oposição entre os bestiais que ocupam a reitoria e os nobres que se envolvem no Projeto Rondon resulta em uma imagem da juventude artificializada, planificada e sem contradições.

\section{A juventude no texto literário}

Se o Estadão constrói uma imagem que procura condicionar a juventude a visões planificadas, em que ora é ingênua e movida por interesses de terceiros, ora é idealista por natureza e defensora dos princípios morais que regem a redação do noticioso, a imagem que o romance As Meninas desenha é bem diferente: enquanto no Jornal o jovem é sempre objeto de uma história 
que é contada por outrem, no texto literário em questão Lorena, Lia e Ana Clara são narradoras de suas próprias vidas. Esse aspecto já faz lançar luzes bem diversas sobre o estudo da juventude universitária durante a Ditadura Militar no Brasil.

Lygia Fagundes Telles, no entanto, faz emergir a partir das vozes de suas personagens uma imagem da juventude que tem características radicalmente diferentes das que vimos até aqui.

Dois aspectos serão destacados a seguir. $\mathrm{O}$ primeiro trata da relação que as três personagens estabelecem entre si, à medida que constroem suas próprias identidades, levantando uma imagem da juventude que é composta por características das três diferentes protagonistas por meio da relação de alteridade. Isso ficará definido logo à epígrafe que abre o livro, em um retrato tirado por uma das freiras que administram o pensionato onde as Meninas moram.

O segundo aspecto trata da sobreposição de características que seriam, a princípio, impossíveis de se misturar: posicionamentos políticos divergentes e crenças religiosas opostas. A cena que retratará esse aspecto é um diálogo entre Lia e Lorena, na segurança do pensionato, quando a morte de um dos companheiros de organização clandestina de Lia faz com que as duas exponham seus sentimentos a respeito da vida, num dos trechos mais sutis e bonitos de todo o romance.

\subsection{A alteridade como meio de construção da identidade da juventude}

No romance, Lygia Fagundes Telles procura construir uma imagem da juventude a partir da sobreposição das imagens das três meninas, Lorena, Lia e Ana Clara. Isso é construído poeticamente a partir da epígrafe do livro, quando as três se reúnem para tirar uma foto, em que cada uma constitui um dos lados de uma pirâmide. $\mathrm{O}$ mesmo trecho é repetido na página 104, quando a autora faz uma referência a um poema de Hilda Hist. É um trecho em terceira pessoa e que tem Lorena como protagonista:

Acertou no canto do espelho o pequeno flagrante que Irmã Clotilde tirara diante do portão: ela no meio de Ana Clara e Lia, as três rindo um riso ardido de sol. 'Não envesga, Ana Clara! E não faça careta, Lorena, você está fazendo careta!'. A pirâmide. A poeta H.H. descreveu-a: - Dentro do prisma, a base, o vértice de suas três pirâmides contínuas — recitou. E baixou o olhar para a própria imagem refletida (TELLES, 2009, p. 104, grifo no original por se tratar de citação).

Lygia brinca com as imagens das três em uma fotografia, que está presa 
na moldura de um espelho no quarto de Lorena. Afasta o ponto de vista para um narrador em terceira pessoa e descreve a cena em que a jovem estudante vê "a própria imagem refletida", no espelho e como parte da constituição da pirâmide, que só faz sentido com a presença de suas duas outras amigas. Esse "pequeno flagrante" é, na verdade, um retrato que a autora constrói da juventude: caleidoscópica, plural e que constrói sentido a partir da alteridade e das relações entre si.

Ao final do romance, no derradeiro parágrafo, quando Lorena, Ana Clara e Lia já se separaram, completando seus arcos narrativos e suas jornadas na história, Lygia recoloca Lorena olhando para o espelho. E, na última frase do texto, a personagem diz: "me vejo de perfil no espelho esfumaçado" (p. 279).

A primeira citação em que o espelho aparece é a síntese simbólica do romance: trata-se de um retrato que captura as três personagens principais, que mantêm um relacionamento como se fossem vértices de uma pirâmide. Ao mesmo tempo, ao olharem-se no espelho, percebem que sua individualidade está garantida, mas profundamente transformada pela relação que estabelecem entre si. Sob esta chave interpretativa, não só as imagens construídas de cada personagem são sobrepostas, como também elas se misturam para criar uma nova configuração, como tintas diferentes que se misturam para criar uma nova coloração. Já sua retomada justo ao desfecho do romance representa a transição efetuada pelas personagens, como se fosse um processo de metamorfose em que o passado seja deixado para trás ao se assumir a forma que perdurará até o futuro.

Giovanni Levi e Jean-Claude Schmitt, na introdução de A História dos Jovens (1996), obra organizada pelos dois e que procura traçar um perfil da juventude ao longo dos tempos sob o olhar da história, afirmam que "a juventude é uma construção social e cultural" e que

\footnotetext{
é justamente o caráter essencial de liminaridade, típico da juventude, conjugado com a maior ou menor brevidade da passagem pela condição de jovem, que caracteriza em última análise (porém de maneira diversa nas diferentes sociedades) a juventude, determinando tanto as atitudes sociais, a atitude dos 'outros' no seu confronto, quanto a visão que os jovens têm de si mesmos (LEVI e SCHMITT, 1996, p. 8-9. Grifos do autor).
}

A autora foi muito feliz, portanto, ao dar forma poética a essa característica da juventude em seu romance, construindo dramaticamente a transitoriedade da juventude, da epígrafe à última linha do romance, num processo coerente e verossímil. Para construir a sensação de permanente 
liminaridade, Lygia utilizou-se da constante mudança de pontos de vista e de narrador; do ponto de vista do enredo, criou três personagens que colocam permanentemente em xeque seu passado a partir das possibilidades de construção de seu futuro, numa dura vida no presente, no cotidiano.

É importante perceber que Lygia Fagundes Telles introduz a leitura do romance por meio de um retrato das três personagens, uma pirâmide com bases muito bem definidas, mas desenvolve individualmente a história de cada uma. À medida que as páginas são lidas, percebe-se um processo de construção das características de cada uma mediante a vivência que estabelecem com as outras. Seus gostos musicais e literários, suas preferências alimentares, seus desejos de futuro, seus modos de falar, de andar e de crer, entre outros, são vistos comparativamente entre si. Constituem-se, portanto, a partir das relações de alteridade que desenvolvem.

Neste sentido, o romance permite uma leitura que não seja totalizante da juventude, mas que a compreenda a partir de sua pluralidade. Por outro lado, não toma a pluralidade como um fato autossuficiente, pois apresenta que esses pontos necessariamente se complementam quando em relação entre si. Em termos simples: não se trata de entender a juventude como um todo sem nuances, nem de entender o jovem como alguém que seja alheio à juventude.

\section{2. "Você parece a Angela Davis"}

Nesta cena, que transcorre a partir da memória de Lorena e é por ela narrada, Lia está triste e tem um momento de sentimentalismo ao se referir aos companheiros de organização. Lorena pergunta de um deles que estaria preso e Lia responde: "tantos estão incomunicáveis. Uma crise infernal. Precisamos de dinheiro, de gente, de tudo. Fico feito doida com os montes de coisas urgentíssimas que devem ser providenciadas" (TELLES, 2009, p. 119).

A conversa continua e Lorena quer saber por qual motivo os cadarços das alpargatas que Lia veste estão limpos, enquanto o restante do calçado está imundo:

'Meus amigos estão todos presos, eu mesma posso ser presa saindo daqui', começou com brandura. 'Manuela está internada como louca e Jaguaribe está morto. Então você se preocupa com o cordão da minha alpargata!'

— Dou importância ao que não tem importância — começo e paro (idem).

Neste momento de total segurança, pois as duas estão em seu utópico, conversando abertamente sobre o que bem entendem, estabelece-se uma relação de intimidade profunda entre as amigas. O que se desenrola a partir deste ponto é significativo para compreender o matizamento de tintas na 
caracterização da juventude que Lygia Fagundes Telles constrói no romance.

Por que às vezes firo Lião quando minha vontade é vê-la contente. Ficou tão triste ali no chão que fui buscar depressa a lata de biscoito e a escova. Ajoelheime e comecei a escovar-lhe os cabelos. Você parece a Angela Davis, eu disse ela sorriu mas senti que seu pensamento continuava lá longe, lá onde Manuela enlouquecera. Onde Jaguaribe fora baleado. Que Manuela era essa? E Jaguaribe? Você nunca me falou nesse(...) (TELLES, 2009, p. 120)

É na referência à ativista Angela Davis que reside o ponto forte desse trecho transcrito. Ao longo de todo o romance, é importante notar, Lorena tece os mais diversos comentários cáusticos a respeito da aparência de Lia, tanto quanto à sua roupa, quanto à sua compleição física, descrevendo-a com traços animalescos, quase bestiais. Neste momento de tristeza, Lorena utiliza as características físicas de Lia como um elogio, como uma forma de demonstrar reconhecimento pelo que a amiga representa. Ela parece dizer que Lia não tem só os cabelos e as feições do rosto parecidos com Angela Davis, mas que ela também é uma pessoa que luta por um mudo profundamente transformado, assim como fazia (e ainda faz) a ativista americana.

Davis foi integrante dos Panteras Negras e obteve notoriedade no período que se descreve no romance, fruto de sua ação política nos Estados Unidos. Presa, mobilizou artistas e ativistas de todas as partes do mundo e de diversas colorações políticas em favor de sua liberdade. O ato de Lorena, que procurava embelezar a amiga com a escovação de seus cabelos, é, portanto, forte. Lia, militante revolucionária de uma organização clandestina, tinha admiração por figuras como a de Angela Davis. O resultado parece não ser alentador, mas revela um elo entre as duas personagens que é muito mais profundo do que a simples oposição aparentada por suas escolhas políticas e estéticas.

Lia tinha um amigo morto, uma amiga internada em um manicômio e o namorado preso. Estava à beira da prisão — ou assim acreditava — e vivia um dos momentos mais conturbados de sua jovem vida. Ao ouvir que se parece com Angela Davis, entretanto, sua reação não é de se confortar, mas de se voltar ao amigo que recém morrera em uma ação política:

Despejei mais uísque em seu copo: coragem, Lião, não fique comprimida, tenho meus santos que me atendem, você não acredita mas deixa comigo. "Se tiver que rezar, reze por Che, entende? É só dele que preciso", disse. (...) Lembrei que Rômulo [irmão de Lorena] também estava morto e comecei a chorar tão sentida que ela se viu obrigada a esquecer seus mortos para me consolar. Disse que não há morte definitiva, nem sequer para ela, uma materialista. Que morte e vida se integram e se completam tão perfeitas como um círculo e por isso meu irmão continuava vivo: a vida precisa da morte para viver, 'Não sei explicar, entende?'. Explicou. (...) (TELLES, 2009, p. 120). 
A retomada da morte estabelece uma nova ligação com Lorena, que passa grande parte do romance falando de seu irmão que morrera enquanto criança, em uma brincadeira com arma com seu outro irmão. Morto por tiro, assim como o baleado Jaguaribe, amigo de Lia. Essa coincidência (coincidência?) na trajetória das duas personagens traz à luz um vínculo aparentemente impossível, mas talvez bastante comum.

Por fim, há o destaque para a relação estabelecida com a religião. Lorena, católica, se dispõe a rezar por Lia, que não só não professa religião, como é materialista. Mas ao invés de negar o desejo de ajuda da amiga, procura uma explicação para a morte que consiga consolar Lorena, ao mesmo tempo em que pede para que a amiga "reze por Che". Isso coloca em cena personagens que dificilmente subiriam no mesmo palco no discurso hegemônico. Che Guevara e a religião; o materialismo e a existência de vida após a morte.

Esta constelação de pequenas características divergentes, que toma corpo na relação estabelecida entre Lia e Lorena, não caberia em um dos editoriais do Estadão. Não seria possível que uma "comunista", uma "agente da mazorca", como Lia, pudesse ser consolada por uma das representantes mais "autênticas" da juventude. O contrário, quando Lorena encontra conforto na explicação de Lia também seria impensável. Ao desnudar essas idiossincrasias em um todo verossímil, o romance, Lygia coloca em xeque a imagem de estudantes que então se produzia publicamente.

Impensável nos discursos hegemônicos, essa representação que aflora no romance nos diz muito sobre a juventude dos anos 1960, uma juventude que talvez fosse muito mais contraditória e sem nitidez, como uma imagem refletida em um espelho esfumaçado, do que os porta-vozes oficiais - fossem eles a grande imprensa ou as lideranças estudantis - costumavam enunciar.

\section{A título de conclusão}

Ao estabelecer vínculos profundos entre pessoas bastante diferentes, em uma situação de cumplicidade e segurança transcorrida sob a proteção de um pensionato de freiras, Lygia apresenta indícios de um cotidiano de jovens que não aparecem nos discursos oficiais. Não haveria espaço para esse tipo de formulação em qualquer dos editoriais do Estadão e certamente essas relações seriam rechaçadas pelas organizações de esquerda que precisavam da clandestinidade para que seus militantes não fossem mortos. 
Muitas vezes, a juventude dos anos 1960 é construída, em termos narrativos, como um grande bloco que reagia ao que acontecia no cenário político e econômico. A leitura deste romance, iluminada pelos conceitos de Certeau, permite identificar contradições nesses discursos.

Esses pequenos pontos de tensão podem levar a um entendimento renovado a respeito dessa juventude, do movimento estudantil e da história da universidade no país neste período. Isso se tornou possível com a utilização do romance As meninas como fonte, pois, com toda a complexidade do discurso literário, foi possível extrair alguns fragmentos que apontassem eixos investigativos para o tema.

A leitura dos editoriais do Estadão, por sua vez, apresenta outra forma de representar a juventude do período estudado. Não cabe ao pesquisador apontar qual está certa ou qual está errada, mas ao colocá-las em confronto, é possível entender um pouco da luta que se processava no interior da sociedade para a cristalização de uma leitura a respeito do período.

Neste sentido é necessário levar em consideração as "dimensões específicas de conflitos entre pontos de vistas, disputas e tensões dos agentes privilegiados e subordinados no campo educacional e os processos de sacralização de memórias sobre a educação" (MORAES, 2015, p. 4), ação que tem em Lygia Fagundes Telles, escritora renomada e reconhecida publicamente, com obras de grande circulação e aceitação, e no jornal $\mathrm{O}$ Estado de São Paulo, influente e tradicional periódico da capital paulista, com participação importante na constituição da universidade no Brasil, dois personagens com lugar de destaque e de protagonismo.

Pois, "se a literatura moderna é uma fronteira extrema do discurso e o proscênio dos desajustados, mais do que o testemunho da sociedade, ela deve trazer em si a revelação dos seus focos mais candentes de tensão e a mágoa dos aflitos" (SEVCENKO, 2003, p. 29).

Afinal, Lião com sua revolução que nunca veio, Lorena e seu futuro marido sempre ausente e Ana Clara com seu triste fim inexorável são personagens que, página a página, carregam consigo tensões e aflições que possibilitam uma compreensão mais dilatada dos significados de ser jovem e estudante sob a égide da Ditadura Militar no Brasil.

\section{Referências}

A CRISE nas nossas universidades. O Estado de São Paulo, São Paulo, 15 
jun. 1968. Notas e informações, p. 3 (1968b).

A SENILIDADE dessa juventude. O Estado de São Paulo, São Paulo, 17 jul. 1970. Notas e informações, p. 3.

ABRAMO, Helena Wendel. Considerações sobre a tematização social da juventude no Brasil. Revista Brasileira de Educação, n. 5 e n. 6, p 25-25, 1997.

AS MENINAS: o novo romance de Lygia Fagundes Telles. O Estado de São Paulo, 09/12/1973. Suplemento Literário, p. 321.

BAKHTIN, Mikhail. Apresentação do Problema. In:

A cultura popular na Idade Média e no Renascimento: o contexto de François Rabelais. São Paulo: HUCITEC/ Brasília: Editora da Universidade de Brasília, 1987. p. $1-50$.

BAKHTIN, Mikhail. O discurso na poesia e o discurso no romance. In: Questões de literatura e de estética. (A teoria do Romance). São Paulo: Editora Unesp, 1993.

BOLAÑO, Roberto. Amuleto. São Paulo: Companhia das Letras, 2008.

BRESSER-PEREIRA, Luiz Carlos. Burocracia pública e classes dirigentes no Brasil. Revista Sociologia e Política, Curitiba, n. 28, p. 9-30, jun. 2007.

CADERNOS DE LITERATURA BRASILEIRA. São Paulo: Instituto Moreira Salles, n. 5, 1998.

CÂNDIDO, Antonio. Literatura e Sociedade. Estudos de teoria e história literária. São Paulo: Companhia Editora Nacional, 1965.

CÂNDIDO, Antonio. O discurso e a cidade. $5^{\text {a }}$ edição. Rio de Janeiro: Ouro sobre azul, 2015.

CANO, Wilson. Crise e industrialização no Brasil entre 1929 e 1954: a reconstrução do Estado Nacional e a política nacional de desenvolvimento. Revista de Economia Política, vol. 35, n. 3, p.444-460, julho-setembro de 2015.

CERTEAU, Michel de. A cultura na sociedade. In: A cultura no plural, $3^{a}$ ed. Campinas: Papirus, 2003. p. 191-220.

CERTEAU, Michel de. A invenção do cotidiano. Artes de fazer. $22^{a}$ ed. Petrópolis: Vozes, 2014.

CERTEAU, Michel de. Teoria e método no estudo das práticas cotidianas. In: 
SZMERECSANYI, Maria Ivone (org.). Cotidiano, cultura popular e planejamento urbano. São Paulo: FAU/USP, 1985. p. 3-19.

CHARTIER, Roger. A história cultural - entre práticas e representações. Lisboa: DIFEL, 1990.

CHARTIER, Roger. O mundo como representação. Estudos Avançados, São Paulo, v. 11(5), p. 173-191, 1991.

CONDENADOS a reviver o passado. O Estado de São Paulo, São Paulo, 18 abr. 1968. Notas e informações, p. 3 (1968a).

CUNHA, Luiz Antonio. A Universidade crítica: o ensino superior na República Populista. $2^{a}$ ed. Rio de Janeiro: Francisco Alves, 1989.

CUNHA, Luiz Antonio. A Universidade reformada: o golpe de 1964 e a modernização do ensino superior. Rio de Janeiro: Francisco Alves, 1988.

FAJARDIE, Frédéric. As jovens damas vermelhas cada vez mais belas. São Paulo: Scritta Oficina Editorial Ltda., 1991.

GASPARI, Elio. A ditadura escancarada. $2^{a}$ ed. Rio de Janeiro: Intrínseca, 2014.

JUVENTUDE universitária em revolta. O Estado de São Paulo, São Paulo, 17 jul. 1970. Notas e informações, p. 3.

LEVI, Giovanni e SCHMITT, Jean-Claude. Introdução. In: (Orgs.).

História dos Jovens. Vol. 1. Da Antiguidade à Era Moderna. São Paulo: Companhia das Letras, 1996.

Lygia Fagundes Telles: entrevista. Revista Brasileira de Psicanálise, São Paulo, v. 42, n. 4, p. 17-20, dez. 2008. Disponível em $<$ http:/ / pepsic.bvsalud.org/scielo.php?script=sci_arttext\&pid=S0486641X2008000400003\&lng=pt\&nrm=iso> Acesso em: 28 set. 2017.

MELHOR para a Rússia. O Estado de São Paulo, São Paulo, 25 mai. 1969. Notas e informações, p. 3.

MENDONÇA, Ana Waleska P. C. A universidade no Brasil. Revista Brasileira de Educação, Rio de Janeiro, n. 14, p. 132-150, abril 2000.

MORAES, Dislane Zerbinatti. Literatura, memória e ação política: uma análise de romances escritos por professores paulistas. 1989. Dissertação (Mestrado em Didática) - Faculdade de Educação, Universidade de São Paulo, São Paulo, 1996. 
MORAES, Dislane Zerbinatti. Narrar e compreender a profissão docente: o exame de fontes literárias na pesquisa em história da educação. In: CONGRESSO INTERNACIONAL CIÊNCIAS, TECNOLOGIAS Y CULTURAS. IV, 2015, Santiago.

MURAKAMI, Haruki. Norwegian Wood. Rio de Janeiro: Objetiva, 2008.

PAES, José Paulo. Ao encontro dos desencontros. Cadernos de Literatura Brasileira, São Paulo, n. 5, p.70-83, 1998.

PINTO, Cristina Ferreira. O Bildunsgroman feminino: quatro exemplos brasileiros. São Paulo: Perspectiva, 1990.

RÉGIS, Sônia. A densidade do aparente. Cadernos de Literatura Brasileira, São Paulo, n. 5, p.84-97, 1998.

SALLES GOMES, Paulo Emílio. Texto da orelha da primeira edição, 1973, In: TELLES, Lygia Fagundes. As Meninas. São Paulo: Companhia das Letras, 2009.

SEVCENKO, Nicolau. Literatura como missão. Tensões sociais e criação cultural na Primeira República. $2^{\mathrm{a}}$ ed., São Paulo: Companhia das Letras, 2003.

\footnotetext{
Abstract: This paper shows the initial results of a research about the undergraduated students's everyday life during military dictatorship in Brazil. It takes place on the reading of Lygia Fagundes Telles's novel called "As Meninas", published in 1973, and confrontates its intepretation by reading editorials about students' protests published by the O Estado de São Paulo newspaper, between 1967 and 1973, in order to indentify the tension points of the representations about the universitary youth produced by those discourses. Michel de Certeau's and Roger Chartier's conceptual repertoire is used to achive that.
}

Keywords: undergraduated students' everyday life; Brazilian Military Dictatorship; Youth. 